\title{
International Symposium on Superalloy 718 and Derivatives Offers Technical Breadth
}

\section{Anthony Banik and Timothy Gabb}

Editor's Note: For additional information on this symposium and to register, visit the meeting website at www.tms.org/superalloy718-2014.

The patent for superalloy 718 was initially applied for in 1958 and awarded to Herb Eiselstein on July 24,1962 . Over the past 52 years, Superalloy 718 has established a firm position in production products, ranging from deep wells in oil patch applications to critical rotating parts in advanced turbofan engines.

During the past half century, a menagerie of alloys has been tailored to address unique process or product needs in the industry. These versatile alloys require advanced melt and conversion practices to assure reproducibility from lot to lot and, subsequently, from part to part. It is fitting that they continue to lead the way to advanced processing technologies, including additive manufacturing, metal injection molding, and cold sprayed coatings, as well as new applications.

The 8th International Symposium

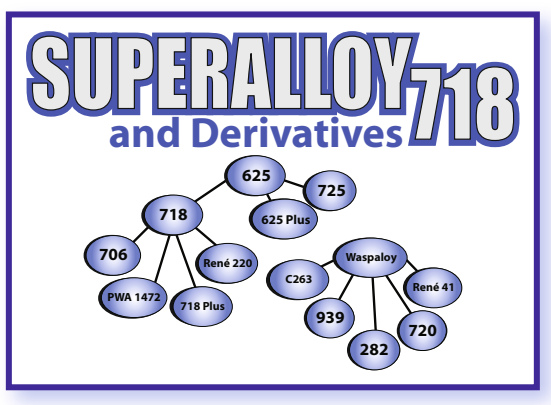

on Superalloy 718 and Derivatives has been designed to provide a very concentrated and intense venture into the fundamental and practical aspects of this alloy group. The conference is scheduled for four days, starting on Sunday night, September 28, 2014, with keynote addresses from two invited speakers-Frank Preli, Chief Engineer, Pratt \& Whitney, and Lee M. Pike, Director, Research and Technology, Haynes International. Each of the subsequent sessions, beginning on Monday September 29, will be initiated with a keynote speaker for the respective topics. The symposium concludes on Wednesday afternoon, October 1 . The conference is centrally

\section{Invited Symposium Speakers}

The following slate of invited speakers will be making presentations focused on leading activities in the focus area for each session at the $8^{\text {th }}$ International Symposium on Superalloy 718 and Derivatives. They represent a broad cross section of organizations, ranging from academia, government agencies, and the metals industry, to specialists from the aerospace and energy industrial arenas.

- Recent Development of Manufacturing Technology on C\&W Superalloy Disc Forgings in China: Jinhui Du, Central Iron and Steel Research Institute

- The Golden Age of Cast Structural Superalloys: Randolph Helmink, Rolls-Royce Corporation

- The Future of Wrought Processing: Dave Furrer, Pratt \& Whitney

- Weldability of Ni-based Superalloys: Joel Anderson, GKN Aerospace

- Comparison of Microstructural Changes in Three Different Ni-base Superalloys After Cyclic Thermo-mechanical Treatment: Daniel Huber, Böhler Schmiedetechnik GmbH \& Co KG

- Microstructural Evolution of Inconel 718 Manufactured Using Powder Bed Fusion Laser Processing: Edward D. Herderick, Rapid Prototype + Manufacturing

- Status of Precipitation Hardened Nickel-Base Alloys Including 718 for Oilfield Applications: Robert Badrak, Weatherford

- Microstructure, Properties, and Characterization: Hamouda Ghonem, University of Rhode Island

- High Pressure Steam Oxidation of Ni-base Superalloys in Advanced Ultra-Supercritical Steam Boilers and Turbines: Gordon Holcomb, National Energy Technology Laboratory

located in Pittsburgh, Pennsylvania, to facilitate access from Europe and Asia, as well as Central and South America.

The 2014 symposium will continue the successful, expanded technical scope established at the last meeting in 2010. Through the joining of multiple metallurgical disciplines, the future of superalloy 718 and derivatives is addressed through an understanding of the fundamental science and processing of the alloys. The symposium is made up of focused sessions which function sequentially, so that the latest technologies are explored to provide a progressive understanding of microstructural development, from alloy composition through final property response. All aspects of the alloy system are explored. Individual sections are also offered and include raw materials, melting, casting, deformation processing, joining, thermal treatments, microstructural evolution, properties, environmental effects, and modeling.

Alloying these complex topics into a meaningful symposium has proven quite challenging. More than 100 abstracts have been received for the technical program. The focus of the symposium is to provide an opportunity for leading technologists in the field to present their work for peer review, as well as develop relationships within the technical community to exchange concepts and formulate new ideas. In order to facilitate this exchange, the conference committee has structured the symposium to balance formal presentations with multiple poster sessions, maximizing opportunities for researchers to interact.

Anthony Banik, ATI Allvac/Allegheny Technologies, can be contacted at anthony .banik@atimetals.com. Timothy Gabb, NASA Glenn Research Center, can be contacted at timothy.p.gabb@nasa.gov.

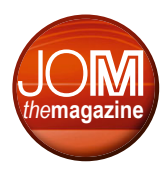

